\title{
Modelling infection spreading control in a hospital isolation room
}

\author{
Carla Balocco, Pietro Liò
}

\footnotetext{
${ }^{1}$ Department of Energy Engineering "Sergio Stecco", Firenze, Italy;

${ }^{2}$ Computer Laboratory, University of Cambridge, Cambridge, UK.

Email:p1219@cam.ac.uk
}

Received 9 May 2010; revised 21 May 2010; accepted 27 May 2010.

\begin{abstract}
This paper investigates the airflow patterns connected to different cough conditions, the effects of these arrangements on the regions of droplet fallout and dilution time of virus diffusion of coughed gas. We focus on some of the physical processes that occur in a double bed hospital isolation room, investigating the effect of the ventilation system on the spread of particles in air. A cough model was carried out and used for the numerical simulation of virus diffusion inside an existent isolation room. Transient simulations of air pattern diffusion and air velocity field, provided by the existing typical HVAC primary air system designed for infectious patients, were performed using CFD. A multiphysics approach, combined Convection-Conduction, Incompressible Navier-Stokes models on non-isothermal air flow and Convection-Diffusion, was used. Simulations results highlighted that the flow field and velocity distribution induced by the high turbulence air inlet diffuser combined with the air return diffusers produce wide recirculation zones near the wall and partial stagnation areas near the ceiling and between the two beds, but lower particle concentration in the room and their shorter spreading distance. This type of analysis is certainly cost effective to identify all the air recirculation zones which can harbour lingering pathogens.
\end{abstract}

Keywords: Airborne Diffusion; Hospital Anfection; VAV System; Transient Simulation; CFD

\section{INTRODUCTION}

The risk of virus particles dispersal in hospitals mainly depends on airflow patterns and on airflow directions changes caused by people's activity, e.g. moving or opening doors. The ventilation system of isolation rooms, operating under closed-door conditions is crucial if the viruses spread and infection must be contained. The quality of the hospital environment is provided by an efficient air-conditioning and ventilating system design, in controlling temperature, humidity, pressure, and indoor air quality. The Heating Ventilation Air Conditioning systems (HVAC) design is fundamental to maintain negative pressure within isolation rooms, to protect health of workers, patients and visitors. This is also necessary to control patient risk from airborne diseases.

In recent years few works have focused on computational models using fluid dynamics approaches to investigated airflow patterns and the related spreading of infection in isolation rooms for different ventilation systems (for example operating under open or closed-door conditions) [1-4]. The main attention of these papers has been the evaluation of the effects of negative pressure in isolation rooms accommodating patients with highly infectious diseases. Recent studies have highlighted that an air velocity above $0.2 \mathrm{~m} \mathrm{~s}^{-1}$ via a doorway effectively prevents the spread of airborne contaminants out of the isolation room in the state of door opening [3,5]. HVAC switch on-off impact on virus and bacteria load has widely investigated recently [6-10].

Techniques such as aerosol particle tracer sampling and computational fluid dynamics can be applied to study the performance of ventilation systems during coughing episodes [4]. HVAC operating for hospitals, must establish optimal airflow pattern inside isolation rooms for infective and in particular for immunesuppressed patients, such that clean air from the airsupply vents may carry the air across infectious sources, and then flow through the exhaust vents completely $[2,3]$. However, it is not sufficient to provide clean environments, due to the higher cross-infections risk, useful guidelines on public health strategies and management can be obtained studying the risky environments by CFD-FEM simulation. In particular CFD simulations based on multiphysics approach can provide a good predictive efficacy, since the possibility to achieve in hos- 
pital stays, accurate experimental measurements is limited and subjected to high costs and difficulties of practical realization. In this paper, referring to obtained results in [11], we developed new transient simulations combining thermo-fluidynamics and diffusion models with heat transfer analysis (convection and conduction). Moreover, we defined a particle tracing and diffusion model taking into account horizontal and vertical components of velocity to carry out a coughing function. Transient simulations were performed to investigate the air flow patterns, distribution and velocity, and the particulate dispersion inside an existing typical hospitalization room equipped with a HVAC primary air system designed for infected patients. We analysed three-dimensional models of the room considering different positions of the patients.

\section{PARTICLES TRACING AND DIFFUSION}

A dispersion model of droplets carrying viruses due to coughing and sneezing was carried out. We believe that our level of modelling details is an effective trade off between accurate description of the chemistry physics process and computational resource. A theoretical general framework would consider the mixture of viruses/ bacteria and water as a two-phase fluid; a complete description would specify virus/bacterial aggregates/ colonies in terms of coupled reaction-diffusion equations for the bacterial and water.

These equations are general in the sense that the reaction, diffusion, pressure, stresses and external forcing terms can be chosen differently for different types of micro-organisms. Further details may take into account different shapes of bacteria (round, spirals, ect) and floating behaviour (stroke-averaged swimmer, shakers" (not self-propelled) and "movers" (self-propelled particles), "pushers" (most bacteria) and "pullers" (for example some algae). Coughing and sneezing produce droplets in size range from less than 1 to up to $2000 \mu \mathrm{m}$.

Typical diameter of a virus, bacteria and fungal spore is respectively $0.02 \div 0.3 \mu \mathrm{m}, 0.3 \div 10 \mu \mathrm{m}$ and $2 \div 5 \mu \mathrm{m}$. Referring to literature we define large droplets those with diameter larger than $60 \mu \mathrm{m}$, and small ones if the diameter is less than $60 \mu \mathrm{m}$ and nucleus droplets when they are less than $10 \mu \mathrm{m}$. Winter season provides optimal conditions for airborne influenza spreading. Coughs and sneezing releases droplets that in cold and low humidity conditions dry out partially the droplets, reducing their size, so to allows the virus to linger longer in the air and the nasal passages making virus transmission more likely. Therefore a multiphysic approach to take into account for temperature variations (in the room) is of key importance. Pathogenic bacteria are generally transported on larger droplets such as skin flakes $(13 \div 17 \mu \mathrm{m}$ diameter) or droplets (ejected with peak diameter $20 \div 40$ $\mu \mathrm{m}$ ) coughing/sneezing generates $10^{4} \div 10^{5}$ droplets. The potential for fomites to remain in the air is due to their final fall velocity that varies with the square of their diameter [4]. Finer particles can remain in the air for long period while larger particles usually sediment to surfaces in those regions of slowly moving air. Particles of $10 \mu \mathrm{m}$ which are responsible of the contagious up to 2 meters distance were taken into account for all the simulations.

A commonly used factor is the Cunningham Slip Correction $\left(\mathrm{C}_{\mathrm{c}}\right)$ which is a correction to the drag coefficient that is used to predict the drag force between a fluid and a particle moving through this fluid. The drag coefficient on each particle must be divided by the Cunningham correction factor, i.e. molecular slip correction that occurs when the size of the particle is of the same magnitude as the distance between gas and water molecules. The particle no longer moves as a continuum in the gas, but as a particle among discrete gas molecules thereby reducing the drag force. The correction factor is greater than 1 which means that the effective particle drag coefficient goes down: this reduction in particle drag is the "particle slip" [12,13]:

$$
C_{c}=1+\frac{\lambda}{D_{p a}}\left[2.34+1.05 \exp \left(-0.39 \frac{D_{p a}}{\lambda}\right)\right]
$$

We considered the free mean path $\lambda$ of a particle, the average distance the particle travels between collisions with other moving particles. The following boundary conditions, that were taken into account, produced a reduction of the Cunningham factor towards its lower boundary of 1: the positive pressure of the isolation room reduces slightly the mean free path with respect to atmospheric pressure; the droplets are initially larger and the evaporation reduces their dimension; the droplets contain glycoproteins, lipidoproteins and lipoglycids constituents of the mucous and also viral particles (and possibly, bacteria); the presence of glycol and lipidproteins could increase the local viscosity of the droplet. The droplet is then subjected to two forces: the force of gravity and the drag force of air resistance [12].

At low velocity $\mathrm{v}$ and low Reynolds number the air resistance $\mathrm{f}$ for a droplet of mass $\mathrm{m}$, is mainly proportional to the viscosity of the medium and to the linear size of the droplet. This provides the horizontal component of motion. The vertical component of sedimentation velocity is:

$$
u_{\text {vertical }}=\frac{\rho D_{p a}{ }^{2} g C_{c}}{18 \eta}
$$

The horizontal component of the velocity is provides 
by $f(\mathrm{u})=(\mathrm{b} \cdot \mathrm{u})$ and then:

$$
u_{\text {horizontal }}=v_{0} \cdot e^{\frac{-b \cdot t}{m}}
$$

where $(b / m)$ has the dimension of time (in seconds as unit system used in this study). The horizontal and vertical components of velocity are also important for fomites formation, i.e. contaminated environmental surfaces which become secondary sources of infection. For a rain drop (approximated as a sphere) the coefficient $b$ has the form $b=(\mathrm{D} \cdot \beta)$. For a spherical drop in air at atmospheric pressure conditions (101325 $\mathrm{Pa}$ ) and temperature of $22^{\circ} \mathrm{C}$, the value of the coefficient $\beta$ is $1.6 \cdot 10^{-4}$ Ns $\mathrm{m}^{-2}[12,13]$. The initial concentration is due to the liquid and then density is 1 ; then velocity which represents the mass transport equation solution is introduced in the software for CFD simulation based on the FEM method [14] as initial condition. The diffusion coefficient of the contaminant is considered to be zero $\left(1.0 \cdot 10^{-10}\right)$ assuming that the effluent, in the form of aerosol, is immiscible in the air. The progressive dilution of the biological effluent concentration is connected to the mass transport mechanism due to the ventilation plant. An expression that provides the cough velocity function $(\mathrm{Co})$, taking into account both the horizontal and vertical components, was carried out:

$$
\operatorname{Co}(\tau)=\frac{1}{(-0.0781207+0.113835 \cdot \exp (15.2864 \cdot \tau))}(4)
$$

At the initial instant is equal to $28 \mathrm{~ms}^{-1}$. For the case of mass transport with diffusion we used the following expression:

$$
N_{\mathrm{H}_{2} \mathrm{O}}=\frac{\rho_{\mathrm{H}_{2} \mathrm{O}} \cdot u_{i n}(\tau)}{m m_{\mathrm{H}_{2} \mathrm{O}}}
$$

assuming for the water molecular mass $18 \cdot 10^{-3} \mathrm{~kg} \mathrm{~mol}^{-1}$.

\section{SOLID MODELLING}

A full-scale isolation room, present in four hospitals in Tuscany (Italy) was considered. It represents the most typical room for hospitalization in Italian hospitals. Solid model of the room is provided in Figure 1. The ventilation plant is a typical HVAC primary air system designed for immune-depressed hospitalization which provides $6 \mathrm{vol} \mathrm{h}^{-1}$ of inlet air and $7 \mathrm{vol} \mathrm{h}^{-1}$ of extraction air [15-18]. The room is ventilated by a commercial turbulence high induction air diffuser located in the centre of the ceiling and in the middle area between the two beds, indicated with A (Figure 1) and the exhaust air is expelled by three return air diffusers located in the ceiling $\mathrm{B}$, in the door of the toilet $\mathrm{C}$ and in the door adjacent to the corridor D.

To ensure effective control of virus containment in the

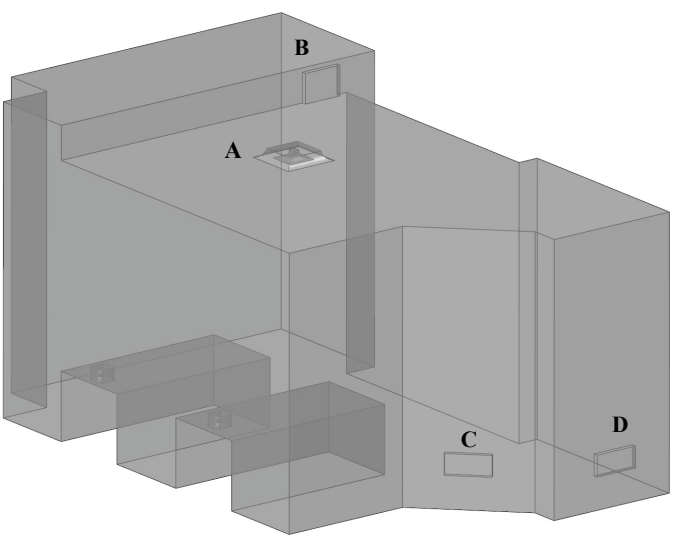

Figure 1. The 3D model of the isolation room.

isolation room, the door must be closed as often as practical so that the air flow can be maintained in a stable state. The scheme of the constant pressures inside the room was calculated referring to this data and to the air diffusers dimensions. For the air inlet, the ceiling return air and the door return air dimensions (transversal section), set constant pressure and air flow rates are respectively the following: $0.36 \mathrm{~m}^{2}$, pressure $26 \mathrm{~Pa}$ and 480 $\mathrm{m}^{3} \mathrm{~h}^{-1} ; 0.157 \mathrm{~m}^{2}, 7 \mathrm{~Pa}$ and $420 \mathrm{~m}^{3} \mathrm{~h}^{-1} ; 0.125 \mathrm{~m}^{2}, 18 \mathrm{~Pa}$ and $130 \mathrm{~m}^{3} \mathrm{~h}^{-1} ; 0.125 \mathrm{~m}^{2}, 18 \mathrm{~Pa}$ and $70 \mathrm{~m}^{3} \mathrm{~h}^{-1}$. The exhaust vents of the ventilation system were set at a constant outlet pressure to maintain the negative pressure within the room as imposed for infectious patients $[15,16,18]$.

The inlet turbulence high induction air diffuser was modelled and gradually changed after several attempts testing the simulation results obtained by [14], to control the real diffusion and turbulence effect of the inlet air on the ceiling, at its fixed velocity. The head of the two patients, lying on two parallel beds, was modelled using a solid geometry to take into account their different positions. On the head surface three outflow surfaces were modelled and used for simulate the inlet surface of the organic effluent (mouth) related to the different position of each patient (Figure 2).

Typical positions of the patients and their different postural conditions (i.e. the first was considered coughing and the second breathing) were modelled: model I for the "supine position", model II for the "face to face" position as while talking each other, and model III for the "overleaf to overleaf" position. For model simplification we considered sneezing and/or coughing once, in simulation time interval, and its process as pulse. The two bed-headboard lamps, the safety lamps on the ceiling, the external opaque wall and the french-window were also modelled. For all the three 3D models the door was kept closed, such that particles diffusion is influ- 


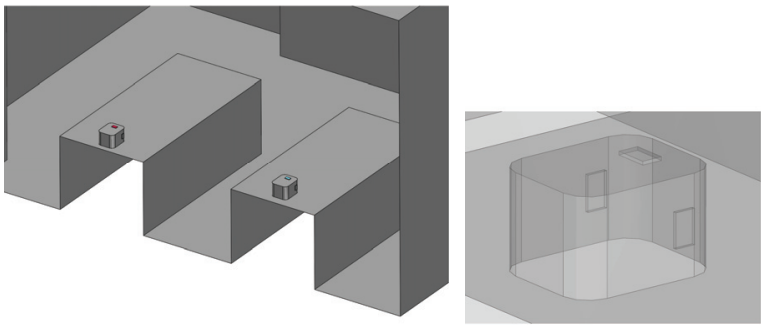

Figure 2. Patients head geometry; head detail (right).

enced by ventilation airflow patterns alone.

\section{SIMULATIONS}

To investigate the temporal dynamics of the ventilation flow and the particles tracing in the conditions of coughing and breathing of the two patients, time dependent simulations combining Incompressible Navier-Stokes, Convection- Diffusion on non-isothermal air flow and Convection-Conduction models, were performed on the three 3D models. First extensive transient simulations were performed employing coarse and normal mesh, checking its quality to obtain solutions with acceptable accuracy. The mesh density was selected to combine solution accuracy with reduction of computational time needed for convergence: a good quality was obtained by 168000 degrees of freedom with 38000 tetrahedral elements for a no-structured grid. Numerical integration is implicit backward Euler method with BDF multistep which guaranteed the quality and robustness of solution: this method provided by [14] automatically chooses the time step on each iteration with checks and controls on the tolerance imposed to the error and to the stability region. The stop-convergence criterion was chosen $1^{*}$ $10^{-4}$ with independence of the results to the mesh density less than $5 \%$ compared to the reference mesh. The direct system solver "UMFPACK" of Unsymmetrical MultiFrontal was used. The initial conditions for this transient computation were obtained by running the simulation starting from a stationary analysis. These first results provided $10^{2} \div 10^{3}$ for Reynolds number which implies a solution under laminar flow conditions. For the indoor climatic conditions, a uniform internal air temperature of $22^{\circ} \mathrm{C}$ and $50 \%$ of relative humidity were assumed as provided by the plant system and suggested $[15,16]$. External climatic data were set at the external design conditions of $0^{\circ} \mathrm{C}$ air temperature and $85 \%$ relative humidity. Transient simulations were performed considering the coughing events during 10 seconds and then they were also carried out for 60 seconds. Input data, subdomains settings, boundary conditions and basic equations used for transient simulations are provided in the appendix. Due to computational time and complexity, the optimization of system solver was carried out: the final computational time for convergence was about 7 hours for each model, using a Processor Pentium 7 Quad Core with 4 GB Ram.

\section{RESULTS}

The ventilation and air diffusion pattern inside the room, at different height, with no coughing and breathing events the patients, is provided in Figure 3. Noteworthy, the flow field and velocity distribution induced by the high turbulence air inlet diffuser combined with the air return diffusers produce wide recirculation zones near the wall and small partial stagnation areas near the ceiling and between the two beds. Variable directions of the air flow due to the high turbulence air inlet diffuser provide its widespread and homogeneous distribution (coanda effect) on the ceiling and then its progressive drop down.

The mean air velocity value of the central diffuser, calculated using simulation results, is $1.36 \mathrm{~ms}^{-1}$, therefore even with reduced surface diffusion, the airflow is laminar the air flow adherence to the ceiling and its fall down. In the zone under the safety light at ceiling, the central inlet air diffuser A and the air return diffuser B, it can be noted the air velocity increasing. Results about temperature distribution inside the room provides values between $22^{\circ} \mathrm{C}$ and $26^{\circ} \mathrm{C}$ due to the "chimney effect" and heat transfer near the heat sources (radiant panel, lamps and patients head; Figure 4). Noteworthy, for small and low temperature variations the effects on air distribution and particle diffusion are not negligible in particular for 60 seconds of simulation time. Thermal buoyancy produces the "chimney effect" even close to the head of patients (vertical component of velocity represented on the surface; Figure 5). The central inlet air diffuser provides turbulent air distribution near the ceiling and its low and progressive downfall. The flow in

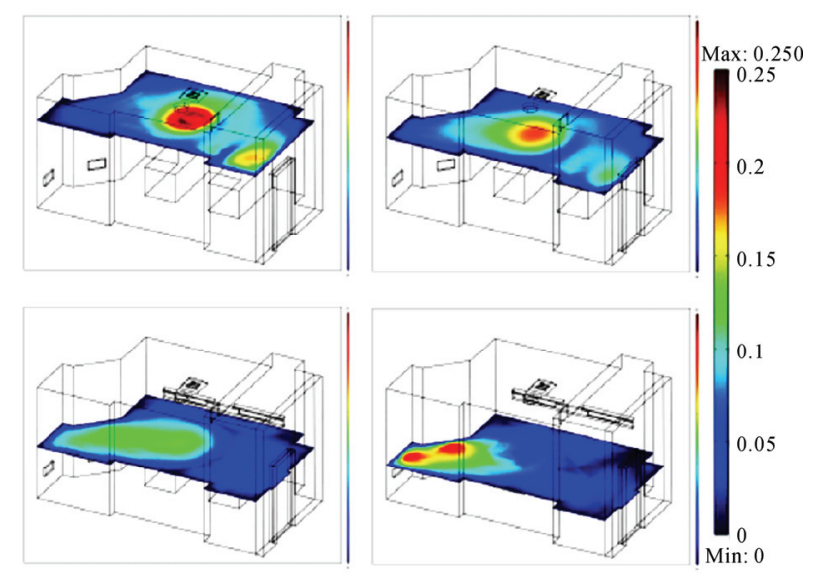

Figure 3. Velocity field at different height; $1 \mathrm{~m}, 1.5 \mathrm{~m}, 2.5 \mathrm{~m}$, $2 \mathrm{~m}$ from bottom-right side to the upper-right side (clockwise). 


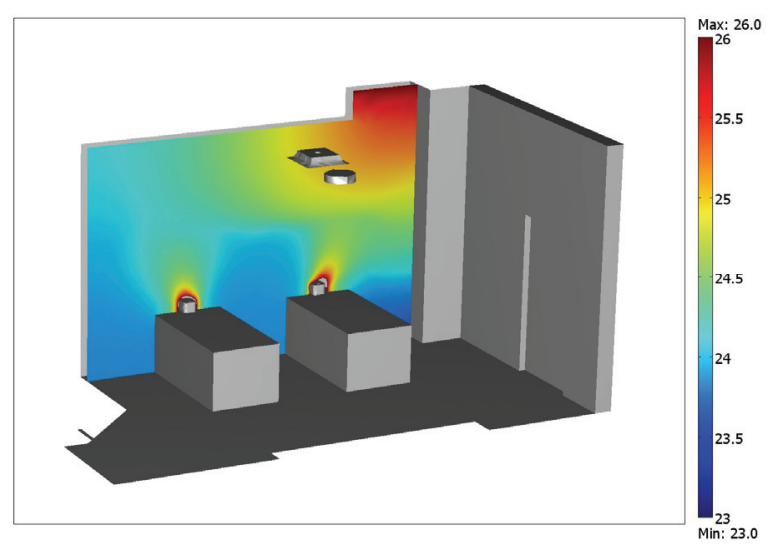

(a)

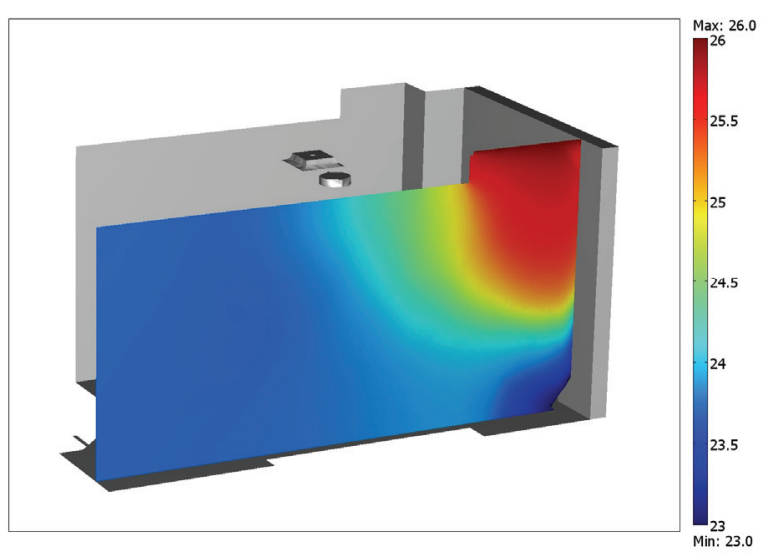

(b)

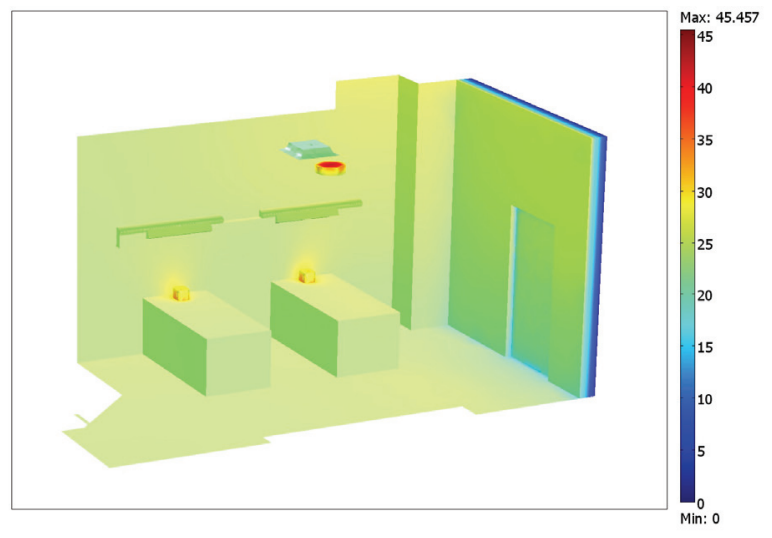

(c)

Figure 4. (a) Temperature field on the wall; (b) slice-detail; (c) entire room.

the region between the three opposite air return diffusers interacts with the local unstable flows, resulting in the generation of an up-flow draft. Particles diffused in the ambient by patient coughing (10 s simulation time) mainly remain in the zone of emission sources. The
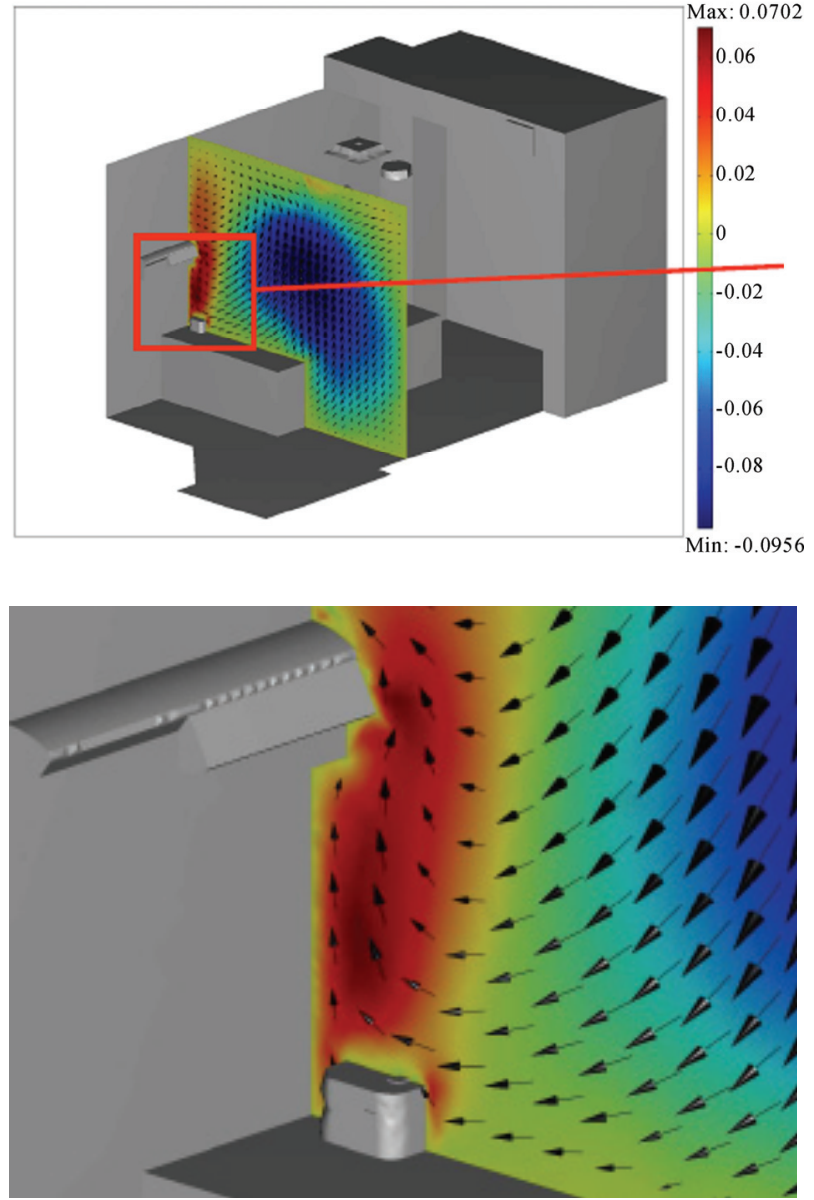

Figure 5. Velocity field - vertical component " $z$ " (left) and detail near the bed (right).

analysis of particle tracing and path distribution connected to their concentration proved the formation of a zone, even though restrained, that should be checked with a microclimatic and contaminant control between the two beds and around the ceiling surface. In the area near the beds the plant guarantees the maximum admissible indoor value of the air velocity and air flow patterns.

The VAV system provides lower particle concentration and shorter spreading distance of particles (both during $10 \mathrm{~s}$ and $60 \mathrm{~s}$ of coughing event); this implies that the transport distance of particle-droplets generated by normal respiration and coughing of patients is limited.

Concerning the dynamics of transient air flow: in the all the 3D models near the mouth of the coughing patient the local air velocity reaches the expected value of 28 $\mathrm{ms}^{-1}$; the transient flow due to the impulse has a length of about 0.5 seconds. About the effluent concentration: in model I the effluent concentration in the form of aerosol achieves the higher values in the time interval of 2-4 seconds and then decreases with time because the 
continuous dilution provided by the air flow inlet; in the model II the effluent concentration, achieves the higher values in the time interval of 3-5 seconds, but during the transient air flow displacement a local effluent stagnation zone is produced between the two beds and small recirculation flows are generated near the patients (Figure 6); in the model III this effluent stagnation reaches the higher values between 4-5 seconds. For the particle path and distance: in the model I, during the first 4 seconds particles collide against the headboard and the head-bed lamp; the trajectories of other particles, in the successive time instants, provide a particle path toward the centre of the room; in the model II, during $10 \mathrm{sec}-$ onds particles go through 1.6-1.8 meters along the orthogonal direction to the second patient, but due to the buoyancy effect, their path takes up in the area between the two bed; in the model III in about four seconds the particles go through 1.4 meters along the orthogonal direction but they do not collide against the wall directing to the floor at the end of transitory. About particle tracing: the particle tracing obtained from the three transient simulations highlights the position during time of the particles due to cough with a diameter of about $1 * 10^{-5} \mathrm{~m}$; the obtained trajectories (Figures 7 and 8) are referred to those particles which position at the initial instant overlap with the surface of the mouth of the first coughing patient and the second breathing. Particles tracing and diffusion obtained by 60 seconds of transitory are different from those obtained by 10 seconds for all the three 3D models.
Particles paths are modified by the inertial/gravitational reduction effect due to thermal buoyancy combined with the air flow displacement in the room. As a matter of fact, the vertical component of particles velocity is prevailing. Comparing results obtained the transient simulations carried out for $60 \mathrm{~s}$ :

1) in the model I at the end of $60 \mathrm{~s}$ of transient simulation, particles path after crossing the bed-head board is oriented to the ceiling due to the thermal buoyancy and air mixing effects (Figure 9);

2 ) in the model II a higher number of particles collide with the second bed and the lying patient. A small number of particles are driven to the ceiling, up to about $2 \mathrm{~m}$, by the air flow displacement and the local turbulence convective flux. This last effect results comparable to that obtained in model I (Figure 10);

3 ) in the model III the all particles during $60 \mathrm{~s}$ of transient simulation collide with the opposite wall. Particles tracing highlights and follows the descending air flow due to the combined thermal and convective effects (air mixing and shorting effect). At the end of transitory the all particles are deposited on the wall (Figure 11).

\section{CONCLUSIONS}

Results indicate the best conditions for the high induction air inlet diffuser and the scheme of pressures imposed in the room to provide the effective means of controlling flows of virus-loaded droplets. Our findings stress that the position of the air-supply inlets in the ceiling and the exhaust vents at the opposite side of the
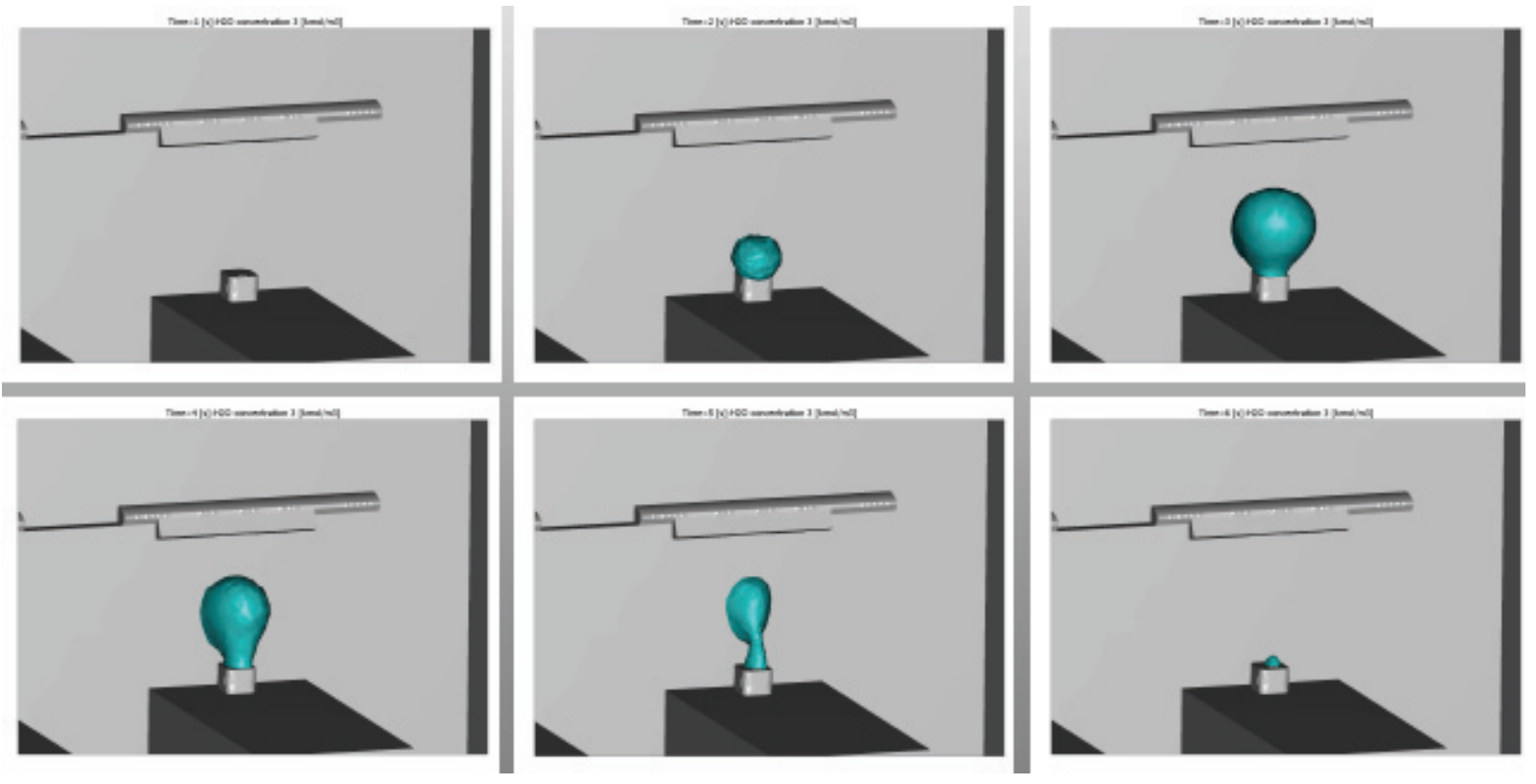

Figure 6. Particle concentration ( $\mathrm{mol} \mathrm{m}^{-3}$ ) during the coughing and breathing of the patients (time from 3 to 6 seconds) - results obtained by the Model II transient simulation. 

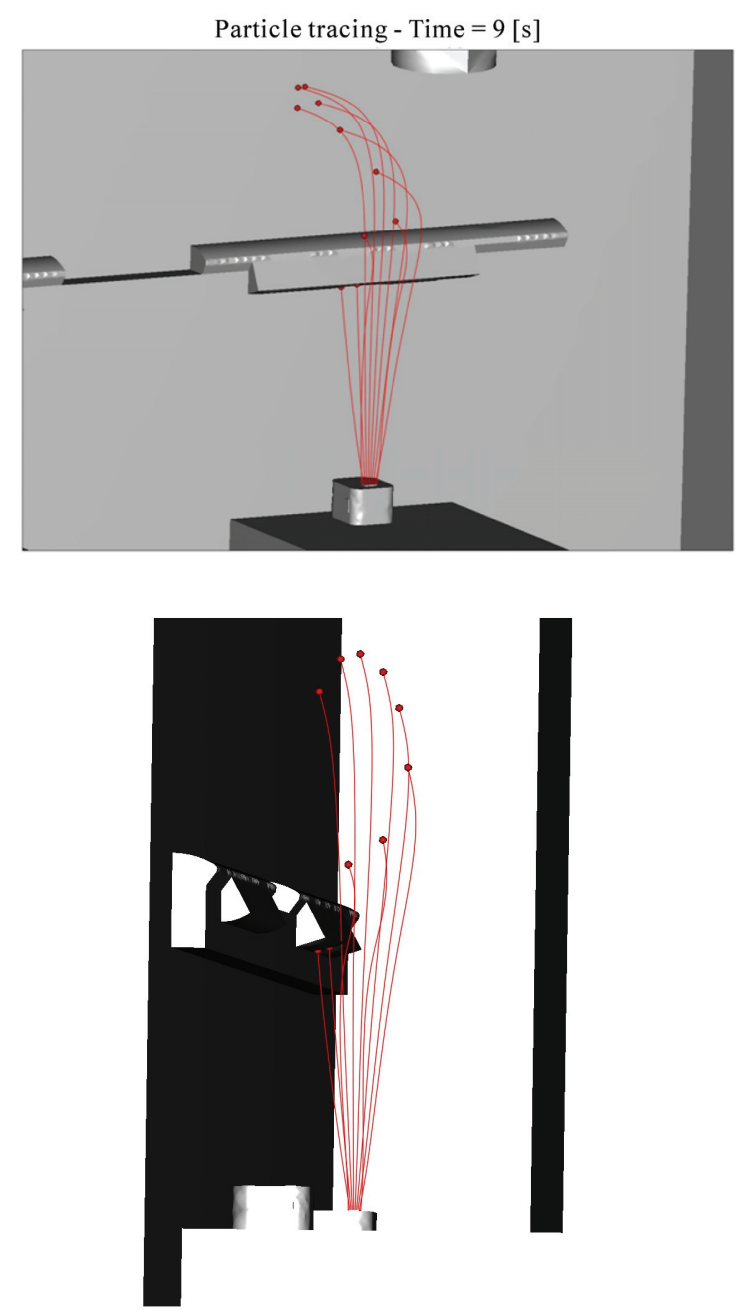

Figure 7. Model I, particle tracing carried out for 10 seconds; detail near the bed-headboard lamp (right).

room and in the ceiling, provide an up-draft effect and infection control efficiency. When the air-supply inlet is located in the middle of the ceiling of the room, and the exhaust vents are positioned in the wall behind the patient beds, the coughed particles and gas are contained at the side of the patient in the region of the exhaust vents. This can minimize the region of coughed gas diffusion and droplet fallout. The high induction air inlet diffuser and the scheme of pressures imposed in the room provide the effective means of controlling droplet flows containing viruses. This type of analysis allows to predict air recirculation zones which can host pathogens. Indeed our analysis of the particle tracing and path distribution combined with their concentration, was effective in identifying examples of such zones between the two beds, around the ceiling surface and on the surface of the bed lamps. Current simulation results yield mean-

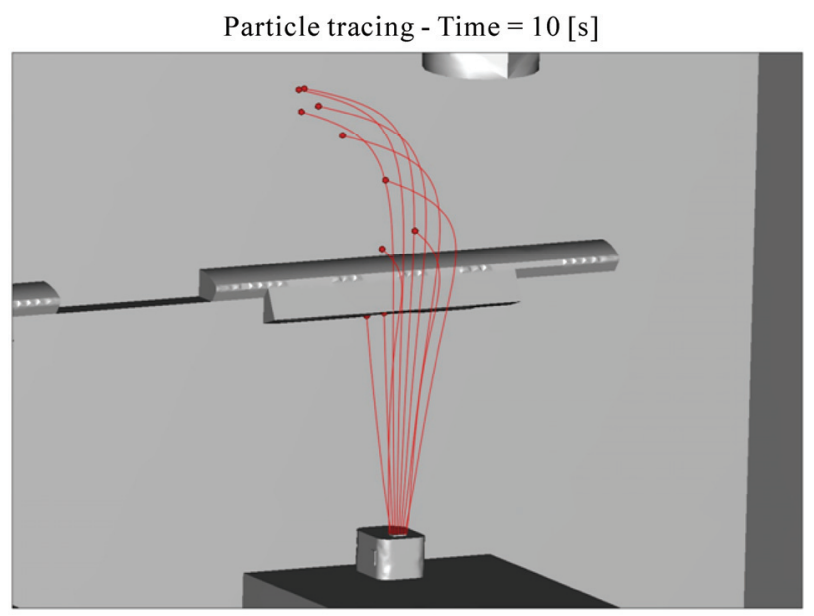

(a)

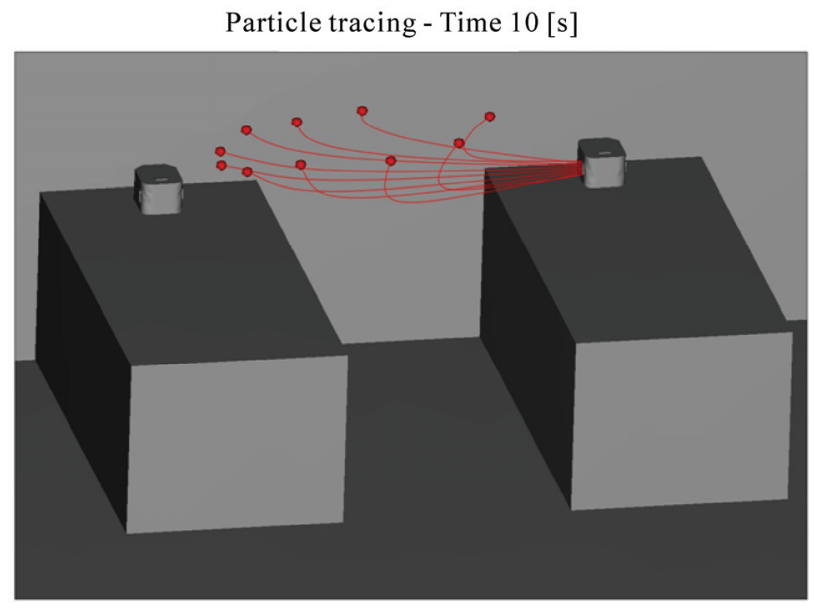

(b)

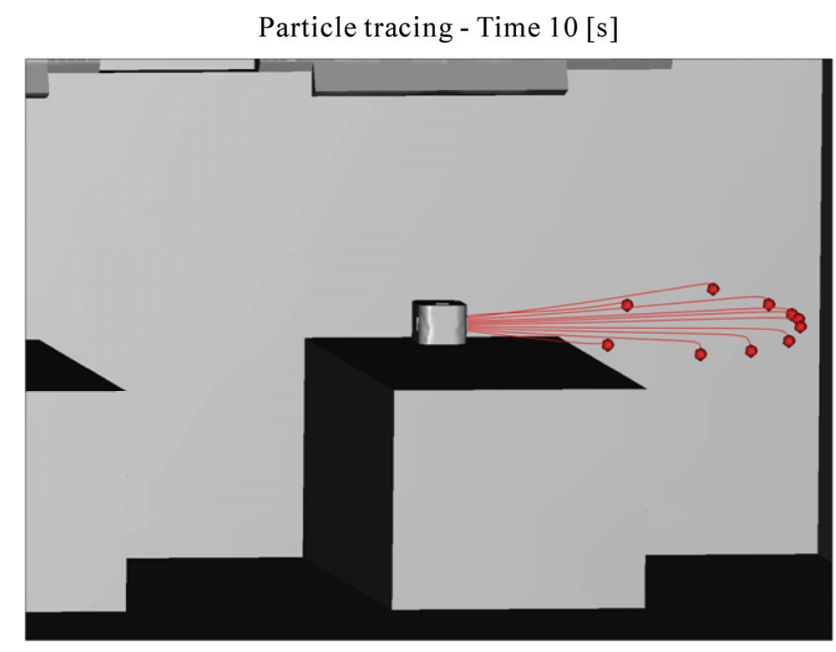

(c)

Figure 8. Particle tracing carried out for 10 seconds. (a) model I; (b) model II and (c) model III. 


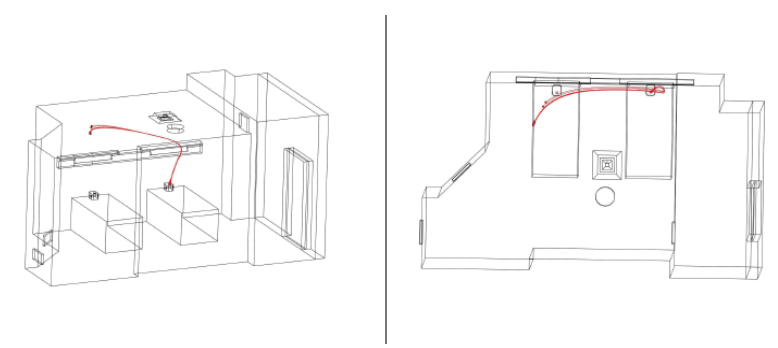

Figure 9. Model I - particle tracing carried out for 60 seconds.

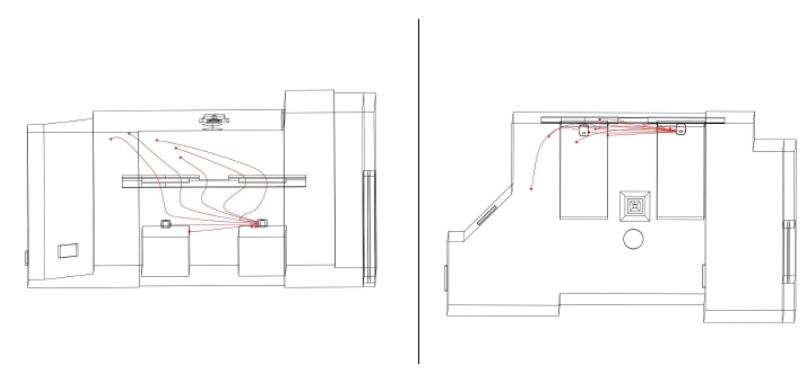

Figure 10. Model II; particle tracing carried out for $60 \mathrm{sec}$ onds.

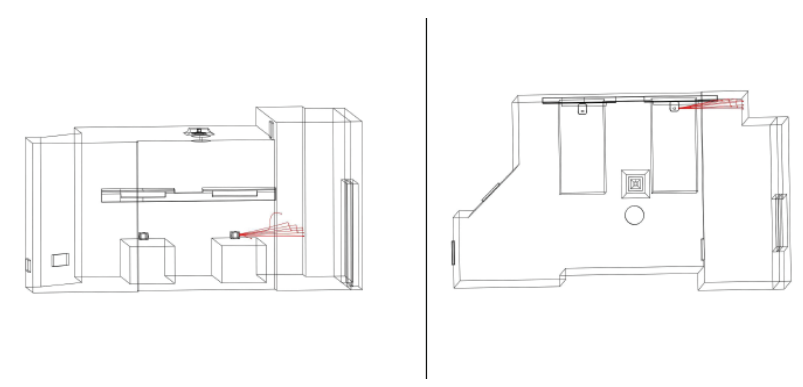

Figure 11. Model III; particle tracing carried out for $60 \mathrm{sec}-$ onds.

ingful findings and recommendations for disease control and careful design and optimization of ventilation in hospitals for also preventing cross infection processes. Our work provides the key insights and developments for hospital management who would like to control the architecture room (e.g. dimensions, form, arrangement of the furniture) the position and dimensions of openings (doors and windows; windows orientation), in particular, type and location of supply and return air diffusers connected to the design of the HVAC system (variable or constant air volume) and the better length and shape of the air-inlet jet.

\section{ACKNOWLEDGEMENTS}

This work is supported by the EC IST SOCIALNETS project, grant agreement number 217141, and the International Technology Alliance, sponsored by the U.S. Army Research Laboratory and the U.K. Ministry of Defense. The authors thank Sani Engineering Consulting Office (Florence, Italy) for provided data on the hospitalization room and plant system.

\section{REFERENCES}

[1] Tang, J., Li, Y., Eames, I., Chan, P. and Ridgway, G. (2006) Factors involved in the aerosol transmission of infection and control of ventilation in healthcare premises. Journal of Hospital Infection, 64(2), 100-114.

[2] Zhao, B., Yang, C.Q., Chen, C., Chao F., Xu D.Y., Sun, L.C., Wei, G. and Li Y. (2009) How many airborne particles emitted from a nurse will reach the breathing zone/body surface of the patient in ISO Class-5 single-bed hospital protective environments? A numerical analysis. Aerosol Science and Technology, 43(10), 9901005.

[3] Stanley, N.J., Kuehn, T.H., Kim, S.W., Raynor, P.C., Anantharaman, S., Ramakrishnan, M.A. and Goyal, S.M. (2008) Background culturable bacteria aerosol in two large public buildings using HVAC filters as long term, passive, high-volume air samplers. Journal of Environmental Monitor, 10(4), 474-481.

[4] Eames, I., Shoabi, D., Klettner, C.A. and Taban, V. (2010) "Movement of airborne contaminants in a hospital isolation room," Journal of the Royal Society Interface, 67576766.

[5] Tunga, Y.-C., Hu, S.-C., Tsaia, T.-I. and Changa, I.-L. (2009) An experimental study on ventilation efficiency of isolation room. Building and Environment, 44(2), 271279.

[6] Walker, J., Hoffman, P., Bennett, A., Vos, M., Thomas, M. and Tomlinson, N. (2007) Hospital and community acquired infection and the built environment - design and testing of infection control rooms. Journal of Hospital Infection, 65(Suppl 2), 43-49.

[7] Soper, M. (2008) Pandemic ready, HVAC systems for worst-case scenarios. Health Facilities Management, 21(10), 49-52.

[8] Bonetta, S., Bonetta, S., Mosso, S., Sampò, S. and Carraro, E. (2009) Assessment of microbiological indoor air quality in an Italian office building equipped with an HVAC system. Environmental Monitoring and Assessment, 161(1-4), 18-28.

[9] Rygielski, L. and Uden, D. (2007) Creating comfort. Nine considerations for selecting the right hospital HVAC system. Health Facilities Management, 20(1), 19-23.

[10] Grinshpun, S.A., Adhikari, A., Honda, T., Kim, K.Y., Toivola, M., Rao, K.S. and Reponen, T. (2007) Control of aerosol contaminants in indoor air: combining the particle concentration reduction with microbial inactivation. Environmental Science Technology, 15(41), 606-612.

[11] Balocco, C., Liò, P. and Sani, L. (2010) Simulazione di un sistema di ventilazione per il controllo degli agenti eziologici nei reparti infettivi. Un caso reale. Condizionamento dell' Aria Riscaldamento Refrigerazione, CdA n.1 febbraio.

[12] Zhao, B., Zhang, Z. and Li, X.T. (2005) Numerical study of the transport of droplets or particles generated by respiratory systems indoors. Building and Environment, 40(8), 1032-1039. 
[13] Cunningham, E. (1910) On the velocity of steady fall of spherical particles through fluid medium. Proceedings of the Royal Society A, 83(561), 94-96.

[14] www.comsol.com

[15] (1995) UNI 10339, Air-conditioning systems for thermal comfort in buildings. General, classification and requirements. Offer, order and supply specifications. Italian
Standard.

[16] (2005) UNI EN 13779, Ventilation for non-residential buildings - Performance requirements for ventilation and room conditioning systems. Italian Standard.

[17] ASHARE-Handbook, HVAC-applications, SI, 1995.

[18] (1991) ASHRAE. Health facilities. ASHRAE Handbook of Applications. S.I. Edition, Atlanta. 


\section{APPENDIX}

The sub-domains settings and boundary conditions, used for all the time dependent simulations, combining the incompressible Navier-Stokes, Convection-Conduction and Convection-Diffusion models on the non-isothermal air flow, are provided in this appendix.

The equations used by CFD FEM transient simulation are the following: Sub-domain settings equation used for Convection-Conduction model:

$$
\delta_{t s} \frac{\rho \cdot C_{p} \cdot \partial T}{\partial \tau}+\nabla \cdot(-k \nabla T)=Q-\rho \cdot C_{p} \cdot u \cdot \nabla T
$$

Sub-domain settings equation used for ConvectionDiffusion model:

Air (fluid)

$$
\delta_{t s} \frac{\delta \mathrm{H}_{2} \mathrm{O}}{\partial \tau}+\nabla \cdot\left(-D \nabla \mathrm{H}_{2} \mathrm{O}\right)=\mathrm{R}-u \cdot \nabla \mathrm{H}_{2} \mathrm{O}
$$

with $\mathrm{H}_{2} \mathrm{O}=$ concentration

Sub-domain settings equation used for the Incompressible Navier-Stokes model:

$$
\rho \frac{\delta u}{\delta \tau}+\rho(u \nabla) u=\nabla\left[-p \cdot I+\eta\left(\nabla u+(\nabla u)^{T}\right)\right]+F
$$

with $\nabla u=0$

The boundary settings used are provided for the Convection-Conduction model (1-5), Convection-Diffusion model (6-8) and then for the Incompressible NavierStokes model (9-14):

1) "insulation" for all the internal walls and doors, the two beds, ceiling, floor, the two bed-headboard lamps and the lamps on the ceiling;

2) "heat flux" for the external wall and the frenchwindow taking into account for the convective coefficient and the external air temperature a constant value respectively $25 \mathrm{~W} \mathrm{~m}^{-2}{ }^{\circ} \mathrm{C}^{-1}$ and $0^{\circ} \mathrm{C}$;

3) "temperature" for the radiant panel on the ceiling, at the fixed value of $26^{\circ} \mathrm{C}$ as suggested [15];

4) "convective flux" for all the return air diffusers;

5) "temperature" for the inlet air diffuser, assuming the constant value of the air inlet of $22^{\circ} \mathrm{C}$;

6) "insulation symmetry" linked to all the walls and doors, the two beds, the ceiling, floor and all the lamps;

7) "convective flux" for all the air return diffuser and also for the air inlet diffuser;

8) for the "supine position" of the patients (Model I), for the "face to face" position (Model II) and then for the "overleaf to overleaf" position (Model III): the boundary condition associated to the mouth of the patient near the toilet was "convective flux"; the boundary condition associated to the mouth of the patient near the wall, was "Inward flux" linked to the "cough function" evaluated by the Eq.4;
9) "no-slip" for the all walls and doors, the two beds, the ceiling and floor;

10) "pressure-no viscous stress" with a boundary type "outlet" for the air return diffuser B, located in the ceiling (Figure 1);

11) "pressure-no viscous stress" with a boundary type "outlet" for the air return diffuser $\mathrm{C}$, located in the door of the toilet (Figure 1);

12) "pressure-no viscous stress" with a boundary type "outlet" for the air return diffuser D, located in the door adjacent to the corridor (Figure 1);

13) "pressure-no viscous stress" with a boundary type "inlet" for the air inlet diffuser A, located in the centre of the ceiling (Figure 1);

14) For model I, model II and model III: the boundary type and boundary condition associated to the mouth of the patient near the toilet were respectively "outlet" and "velocity" with the fixed velocity (normal outflow) of $0.9 \mathrm{~ms}^{-1}$; the boundary type and boundary condition associated to the mouth of the patient near the wall, were respectively "inlet" to take into account his breathe and "velocity" with a velocity value associated to the cough function.

Input data used were the following:

1) thermal conductivity, density, viscosity conductivity and specific heat of the air were considered constant;

2) the density, molecular mass $\left(18^{*} 10^{-3} \mathrm{~kg} \mathrm{~mol}^{-1}\right)$ and diffusion coefficient of the water $\left(1 * 10^{-10} \mathrm{~m}^{2} \mathrm{~s}^{-1}\right)$ were considered constant;

3 ) inlet velocity at the initial instant due to the cough was considered constant $\left(28 \mathrm{~ms}^{-1}\right)$;

4) the inlet/outlet breathe velocity was considered constant $\left(0.9 \mathrm{~ms}^{-1}\right)$;

5) inlet air temperature form the central air diffuser was taken at $22^{\circ} \mathrm{C}$ as provided by the engineering consulting office;

6) mean ambient temperature and relative humidity were fixed to the values provided by the plant at $22^{\circ} \mathrm{C}$ and $50 \%$;

7) sensible and latent loads due to "rest and sat" activity, taking into account the clothes and the ambient air temperature of $22^{\circ} \mathrm{C}$, are respectively $76 \mathrm{~W}$ and $26 \mathrm{~W}$ for the standard body area of $1.8 \mathrm{~m}^{2}$ from DuBois formula. Then taking into account the mean body conductivity and the head volume, the specific dissipation heat and total power of the head were evaluated;

8) the pressure scheme inside the room was calculated referring to the HVAC-VAV primary air system and to the air diffusers dimensions. The exhaust vents of the ventilation system were set at a constant outlet pressure to maintain the negative pressure within the room as imposed for infectious patients;

9) taking into account the thermo-physical properties 
of the different constituent layers, the equivalent thermal transmittance of the external wall and french-window were evaluated and considered constant, (external wall $0.287 \mathrm{~W} \mathrm{~m}^{-2} \mathrm{~K}^{-1}$; french-window $1.048 \mathrm{~W} \mathrm{~m}^{-2} \mathrm{~K}^{-1}$ );

10) specific dissipating heat and power for the two bed-headboard lamps were calculated taking into ac-

\section{NOMENCLATURE}

\section{Latin}

B coefficient

C Cunningham factor

Co coughing function

$\mathrm{C}_{\mathrm{p}}$ heat capacity at constant pressure $\left(\mathrm{J} \mathrm{kg}^{-1} \mathrm{~K}^{-1}\right)$

D diameter (m)

$F$ air resistance

$\mathrm{G}$ acceleration of gravity $\left(\mathrm{m} \mathrm{s}^{-2}\right)$

$M$ mass $(\mathrm{kg})$

Mm molecular mass

$\mathrm{N}$ mass transport with diffusion $\left(\mathrm{kgs}^{-1}\right)$

$\mathrm{Q}$ heat source $\left(\mathrm{W} \mathrm{m}^{-3}\right)$

$\mathrm{R}$ thermal resistance $\left(\mathrm{m}^{2} \mathrm{~K} \mathrm{~W}^{-1}\right)$

Re Reynolds number count their lighting parameters (compact fluorescent, $4000 \mathrm{~K}$ colour temperature, $58 \mathrm{~W}$ absorbed power, 1350 $\mathrm{lm}$ lighting flux);

11) safety lamps on the ceiling were considered barrier to the air displacement.

T temperature $\left({ }^{\circ} \mathrm{C}\right)$

$\mathrm{U}$ velocity $(\mathrm{m})$

Greek

B coefficient

$\lambda$ mean free path (m)

$\eta$ dynamic viscosity (Pa s)

$\mu$ air viscosity (Pa s)

$\mathrm{P}$ density $\left(\mathrm{kg} \mathrm{m}^{-3}\right)$

$\tau$ time

Footer

C correction

$\mathrm{H}_{2} \mathrm{O}$ water

In inlet

$P$ pressure

Pa particle 